\title{
Conformational Properties of Arenicins: From the Bulk to the Air-Water Interface
}

\author{
Oksana G. Travkova, ${ }^{[a]}$ Jörg Andrä, ${ }^{[b]}$ Helmuth Möhwald, ${ }^{[a]}$ and Gerald Brezesinski* ${ }^{[a]}$
}

\begin{abstract}
The structures of two antimicrobial peptides (arenicin Ar-1 and its linear derivative $\mathrm{C} / \mathrm{S}-\mathrm{Ar}-1$ ) are studied in different solutions and at the air-water interface using spectroscopic methods such as circular dichroism (CD) and infrared reflection absorption spectroscopy (IRRAS) as well as grazing incidence $X$-ray diffraction (GIXD) and specular X-ray reflectivity (XR). Both peptides exhibit similar structures in solution. In the buffer used for most of the experiments the main secondary structure elements are $22 \% \beta$-turn, $38 \% \beta$-sheet and $38 \%$ random coil. The amphiphilic peptides are surface-active and form a Gibbs mon-
\end{abstract}

olayer at the air-buffer interface. The surface activity is drastically increased by increasing the ionic strength of the subphase. The $\beta$-sheet layer is quite stable and can be compressed to higher surface pressures. This adsorption layer is very crystalline. Bragg peaks corresponding to an interstrand distance of $4.78 \AA$ and to an end-to-end distance have been observed. This end-to-end distance can be connected with the observed differences in the layer thickness leading to the assumption that the peptides form a hairpin which is bended depending on the interactions with the counterions.

\section{Introduction}

The problem of the growing resistance of causative organisms to antibiotics and the alarming forecast for the complicated synthesis of new drugs of this class turned scientists back to nature in their search for new anti-infective therapeutics. The fact that many organisms have used certain substances in their defense system since the beginning of evolution testifies to a feasible problem solution. Antimicrobial peptides (AMPs) are a universal feature of the defense system of virtually all life forms, with representatives found in organisms ranging from bacteria to plants and invertebrate and vertebrate species, including mammals. ${ }^{[1,2]}$ They are a part of the ancient, non-specific innate immune system. The isolation of large numbers of AMPs from different organisms within the last 3 decades $^{[3]}$ makes it possible to classify these peptides, ${ }^{[4]}$ and a study of their properties and behavior in different environments allows one to judge their modes of action. ${ }^{[5]}$

Arenicins, recently discovered in coelomocytes of marine polychaeta lugworm Arenicola marina, represent an interesting class of AMPs. ${ }^{[6]}$ Peptides of this family exhibit excellent activity from low-salt to high-salt conditions against gram-positive and gram-negative bacteria, and fungi ${ }^{[6-8]}$ Arenicins are short 21residue positively charged peptides, which have a single disulfide bond Cys3-Cys20, forming a large 18-residue ring, and have no sequence homology to any previously identified AMPs. To determine the role of this disulfide bond in their antimicrobial activity, peptides with two disulfide bonds were also synthesized by substitution of valines by cysteines ${ }^{[9]}$ and a linear derivative by substitution of cysteines by serins (C/S-Ar1). ${ }^{[10,11]}$ Positively charged amino acid residues were also considered as playing significant role in biological activity, but the replacement of arginine residues by lysines does not support the necessity of arginine. ${ }^{[11]}$
The tertiary structures of the two natural cyclic arenicin isoforms were determined in solution by NMR spectroscopy. Both exhibit prolonged $\beta$-hairpins, stabilized by several non-covalent interactions such as hydrogen bonds, hydrophobic interactions, and $\pi$-cation interactions between tyrosine and arginine side chains. ${ }^{[10,12,13]}$ The $\beta$-hairpin of arenicin- 1 has a significant right-handed twist leading to an amphiphilic surface structure. $^{[12]}$ Other investigations ${ }^{[14]}$ showed the dimerization of two peptide monomers in solution by non-covalent parallel asymmetric association stabilized by eight intermolecular hydrogen bonds. Due to this association, mainly aromatic and hydrophobic residues are locked between two $\beta$-hairpins as well as two positive charges from each monomer.

The present work is focused on the interfacial properties of cyclic arenicin-1 (Ar-1) and its linear derivative C/S-Ar-1. Biological studies ${ }^{[7,10,11]}$ have shown that both peptides exhibit high antibacterial activity against gram-negative bacteria (Escherichia coli, Pseudomonas aeruginosa) and gram-positive bacteria (Staphylococcus aureus, Staphylococcus epidermidis) with the minimal inhibitory concentrations (MIC) values ranging from 2.0 to $8.0 \mu \mathrm{M}$ for Ar-1 and 4.0-16.0 $\mu \mathrm{M}$ for C/S-Ar-1. The linear peptide exhibited a higher structural flexibility, ${ }_{1}^{[10]}$ which results in the slightly impaired antibacterial activity, higher susceptibility to protease digest, and significantly different pore charac-

\footnotetext{
[a] O. G. Travkova, Prof. H. Möhwald, Prof. G. Brezesinski

Max Planck Institute of Colloids and Interfaces

Science Park Golm, 14476 Potsdam (Germany)

Fax: (+ 49) 331-567-9222

E-mail:brezesinski@mpikg.mpg.de

[b] Dr. habil. J. Andrä

Division of Biophysics

Leibnitz Center for Medicine and Biosciences

Research Center Borstel, Parkallee 10, 23845 Borstel (Germany)
} 
teristics in planar lipid bilayer experiments, when compared with the natural peptide Ar-1. ${ }^{[1]]}$ The linear peptide displayed also lower cytotoxicity in experiments with human erythrocytes. Studies performed using a Langmuir trough coupled with other techniques can complete the existing information on arenicins, and give the necessary introduction into an understanding of processes accompanying the peptide-membrane interaction. The in situ structure and the orientation of the studied peptides at the air-water interface have been determined using infrared reflection absorption spectroscopy (IRRAS). Specular X-ray reflectivity (XR) and grazing incidence $X$-ray diffraction (GIXD) measurements have been performed to provide information on the adsorption layer on a molecular level.

\section{Results and Discussion}

\subsection{Structure of Arenicins in Aqueous Solutions}

The secondary structure of Ar-1 and its linear derivative C/S-Ar1 in water, phosphate buffer with and without additional salt (Figure 1), in TFE and in the presence of differently charged amphiphiles (Figure 2) was determined by CD measurements. The CD spectra of both peptides show similar structures in water, buffer at $\mathrm{pH}$ 5, 7, 9 (not shown), sodium chloride solution, and in nonionic and cationic surfactants solutions above and below their cmc (not shown). All spectra have the same shape as shown in Figure 1. A global minimum below $200 \mathrm{~nm}$ indicates a significant random coil population. A maximum

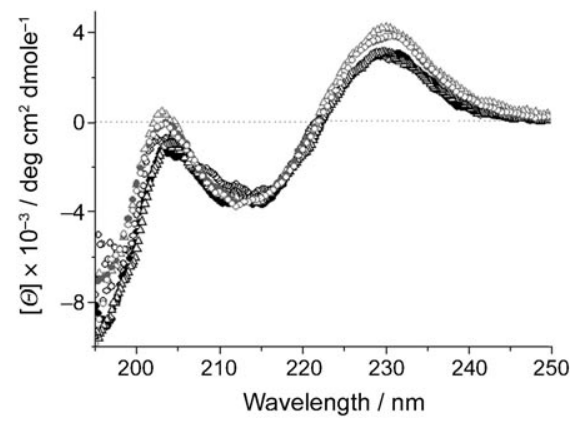

Figure 1. CD spectra of $C / S-A r-1$ (black) and Ar-1 (gray) in water $(\triangle)$, in phosphate buffer (1 mM, pH 7.4) (๑), and in buffer with $150 \mathrm{~mm} \mathrm{NaCl}(\circ)$.

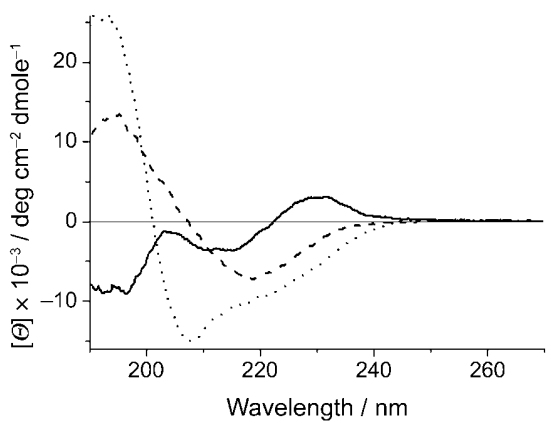

Figure 2. $C D$ spectra of C/S-Ar-1 in phosphate buffer (1 mm, pH 7.4) (-), in TFE (.....), and in SDS solution (----). around $204 \mathrm{~nm}$ is typical for $\beta$-turn II conformation. The cyclic arenicin shows a less prominent negative feature indicating a larger population of $\beta$-type II turn in the cyclic peptide. The minimum near $210-215 \mathrm{~nm}$ is blue-shifted indicating $\beta$-turn III/ I presence. The maximum at $230 \mathrm{~nm}$ is due to the contribution of aromatic side chains, which is more pronounced for Ar-1. Differences in spectra possibly arise from a dimerization of the cyclic molecules shown for arenicin isoform 2, Ar- $2{ }^{[14]}$ while the linear molecules are not able to aggregate. Fitting of the CD data led to $22-23 \% \beta$-turn, 37-39\% $\beta$-sheet and 38\% random coil for Ar-1 and C/S-Ar-1 in buffer (Table 1). The presence of SDS changes these values only slightly, but the influence is clearly visible in the spectra (Figure 2).

\begin{tabular}{|c|c|c|c|c|}
\hline Solution & $\alpha$-helix & $\beta$-sheet & $\beta$-turn & random coil \\
\hline Ar-1 in buffer, $\mathrm{pH} 7.4$ & 0 & 39 & 22 & 38 \\
\hline C/S-Ar-1 in buffer, $\mathrm{pH} 7.4$ & 2 & 37 & 23 & 38 \\
\hline C/S-Ar- 1 in TFE & 42 & 19 & 17 & 23 \\
\hline $\mathrm{C} / \mathrm{S}-\mathrm{Ar}-1+\mathrm{SDS}$ (above $\mathrm{cmc}$ ) & 6 & 42 & 20 & 32 \\
\hline
\end{tabular}

The experiments with TFE and SDS were performed to demonstrate that the linear peptide C/S-Ar-1 is able to adopt other conformational states as well (Figure 2). In TFE solution, the CD spectrum is typical for a mainly $\alpha$-helix conformation with one maximum around $190 \mathrm{~nm}$ and two minima at 208 and $225 \mathrm{~nm}$. Whereas nonionic and cationic surfactants had no effect on the secondary structure, the anionic SDS, below and above its $\mathrm{cmc}$, leads to a clear change in the CD spectrum. Surprisingly, this drastic change does not result in pronounced changes of the fractions of secondary structure motifs derived from the simulations. Presumably these simulations do not take into account properly the aromatic residues contributing to the signal around $230 \mathrm{~nm}$.

\subsection{Adsorption to the Air-Water Interface}

The amphiphatic structure of C/S-Ar-1, which was described earlier, ${ }^{[10]}$ is the reason for the observed surface activity. The adsorption kinetics can be followed by using the Langmuirfilm balance. The peptide was dissolved in the subphase, and the surface pressure was monitored starting from a bare surface $\left(0 \mathrm{mN} \mathrm{m}^{-1}\right)$. Figure 3 (curves 2-5) and Figure 4 (curves $1 \mathrm{~b}$, $2 \mathrm{a}, 2 \mathrm{~b})$ show that the adsorption of $\mathrm{C} / \mathrm{S}-\mathrm{Ar}-1$ to the air-water interface leads to a decrease of the surface tension (increase of the surface pressure). The adsorption kinetics is clearly concentration-dependent. As expected the peptide adsorbs to the air-water interface faster from more concentrated solutions. The plateau on the plots corresponds to the adsorption equilibrium. The concentration of $200 \mathrm{~nm}$ is obviously not high enough to reach a surface concentration of the peptide molecules which leads to a measureable change in the surface pres- 


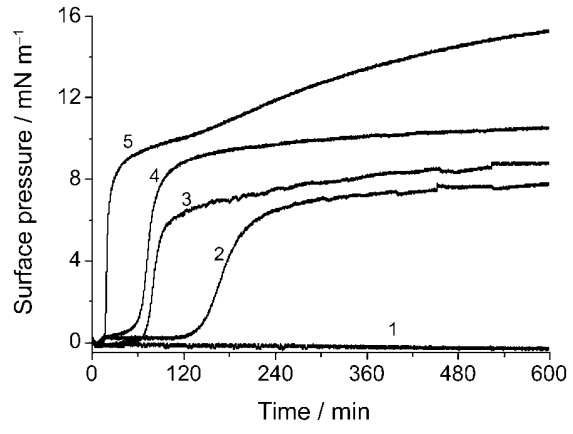

Figure 3. Adsorption kinetics at the air-buffer interface (in presence of $150 \mathrm{~mm} \mathrm{NaCl}$ ) using different C/S-Ar-1 concentrations: 1) $200 \mathrm{~nm}, 2) 300 \mathrm{~nm}$, 3) $400 \mathrm{~nm}$, 4) $500 \mathrm{~nm}$, 5) $1 \mu \mathrm{M}$.

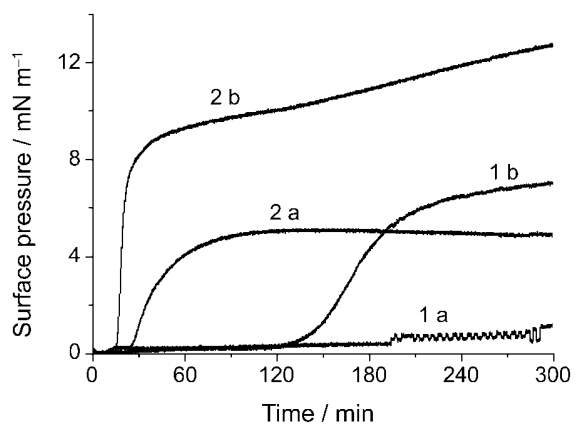

Figure 4. Adsorption kinetics at the air-buffer interface using different $\mathrm{C} / \mathrm{S}$ Ar-1 concentrations: 1) $300 \mathrm{nM}$, 2) $1 \mu \mathrm{M}$ and different salt content: a) without additional salt, b) in the presence of $150 \mathrm{~mm} \mathrm{NaCl}$.

sure (Figure 3, curve 1). The critical concentration of sufficient coverage is between 200 and $250 \mathrm{~nm}$. For the $500 \mathrm{~nm}$ solution, the equilibrium adsorption pressure is $9 \mathrm{mN} \mathrm{m}^{-1}$. In the case of a $1 \mu \mathrm{M}$ solution (Figure 3, curve 5), the peptide adsorption seems to lead to the same equilibrium value of $9 \mathrm{mN} \mathrm{m}^{-1}$, but after short time the adsorption continues and the surface pressure increases further. This can be a sign of either a stepwise adsorption process (formation of a second adsorption layer) or a reorientation of the peptide molecules in the monolayer allowing more peptide to accommodate.

The C/S-Ar-1 has a pronounced surface activity in $1 \mathrm{~mm}$ phosphate buffer with $150 \mathrm{~mm} \mathrm{NaCl}$, but much less activity is observed in solution without additional $\mathrm{NaCl}$ (Figure 4). The same phenomenon of the effect of salt on the surface activity was independently observed for other antimicrobial peptides. $^{[15-17]}$ The decrease of the ionic strength of the $1 \mu \mathrm{M} \mathrm{C/S}$ Ar-1 solution leads to the decrease of the equilibrium surface pressure from 9 to $5 \mathrm{mN} \mathrm{m}^{-1}$. Adsorption from a $1 \mu \mathrm{M}$ peptide solution in buffer does not reveal the stepwise nature of the adsorption process observed in the presence of additional $\mathrm{NaCl}$, and a $300 \mathrm{~nm}$ peptide solution does almost not change the surface tension in the absence of $\mathrm{NaCl}$. The adsorption experiments with different salts $\left(\mathrm{NaCl}, \mathrm{NaBr}\right.$ and $\left.\mathrm{Na}_{2} \mathrm{SeO}_{4}\right)$ at the same ionic strength have shown that the type and the charge value of anions do not play a significant role for peptide surface activity.
All further experiments were performed in the presence of $150 \mathrm{~mm} \mathrm{NaCl}$. Moreover, the peptide concentration of $200 \mathrm{~nm}$ (when the surface pressure always remains zero) was found to be high enough for the investigation of the adsorption process and determining the peptide secondary structure at the airwater interface using IRRAS. The amide I band is associated with $\mathrm{C}=\mathrm{O}$ stretching vibrations, and the amide II band results from $\mathrm{C}-\mathrm{N}$ stretching and $\mathrm{N}-\mathrm{H}$ bending vibrations. They can be observed in regions of wavenumbers between 1700 and $1500 \mathrm{~cm}^{-1}$ (amide I: $1700-1620 \mathrm{~cm}^{-1}$; amide II: $1580-$ $\left.1520 \mathrm{~cm}^{-1}\right)$. The amide $\mathrm{A}$ band is assigned to the amide stretching mode of the peptide backbone and appears near $3260 \mathrm{~cm}^{-1}$. The broad band at $3600 \mathrm{~cm}^{-1}$, which corresponds to the $\mathrm{O}-\mathrm{H}$ stretching vibration, is important for monitoring changes in the monolayer thickness. During adsorption, amide and water bands appear and grow indicating an increasing peptide concentration and layer thickness/density at the interface (Figure 5).

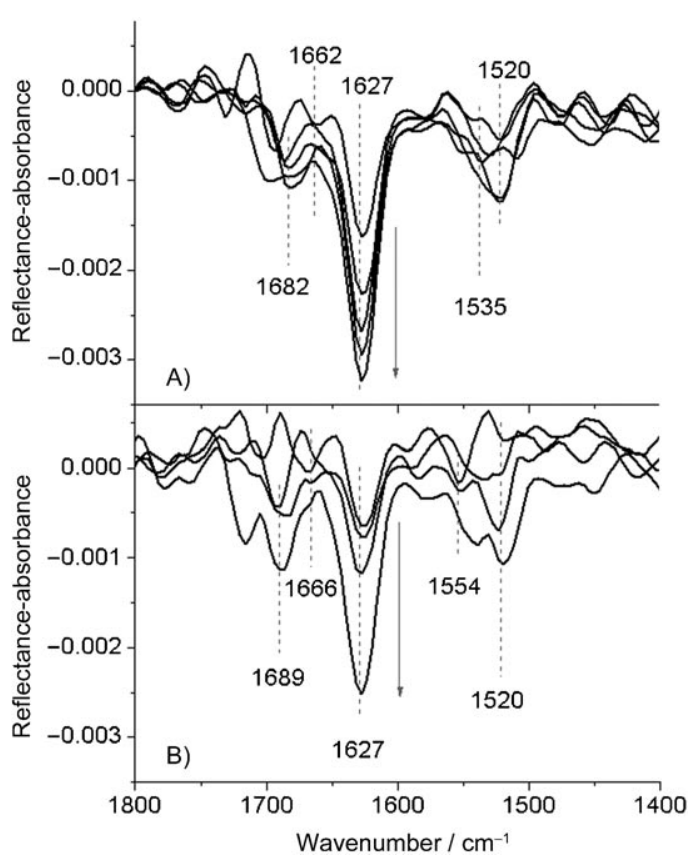

Figure 5. IRRA spectra of A) C/S-Ar-1 and B) Ar-1 during the adsorption to the air-buffer (containing $150 \mathrm{~mm} \mathrm{NaCl}$ ) interface. Spectra have been recorded every $30 \mathrm{~min}$ at an angle of incidence of $40^{\circ}$ with $p$-polarized light. The arrow shows the direction of changes: The intensity of amide bands increases with time. The equilibrium state is characterized by constant intensities. The equilibrium surface pressure of the $200 \mathrm{~nm}$ peptide solutions used remains at $0 \mathrm{mN} \mathrm{m}^{-1}$.

The linear and cyclic peptides exhibit similar behavior and do not change their conformation at the air-water interface during the adsorption process. The amide I band splits into one strong band at $1627 \mathrm{~cm}^{-1}$ and one weaker band at $1690 \mathrm{~cm}^{-1}$ indicating antiparallel $\beta$-sheets. A weak splitting of this last band shows the presence of a $\beta$-turn. ${ }^{[18,19]}$ After approaching the equilibrium state at the air-water interface, the band intensities do not change anymore. Comparison of inten- 
sities of the amide I band using s- and p-polarized light (Figure 6) shows that the $\beta$-sheet is lying flat at the interface.

The adsorption layers of both $\mathrm{C} / \mathrm{S}-\mathrm{Ar}-1$ and $\mathrm{Ar}-1$ are stable and can be compressed to a certain extend (Figure $7, \pi / \mathrm{A}$-isotherms are inserted) showing that the kinetics of desorption is much slower than that of adsorption. Water bands in the spectra of Figure 7 show that the effective thickness (packing den-

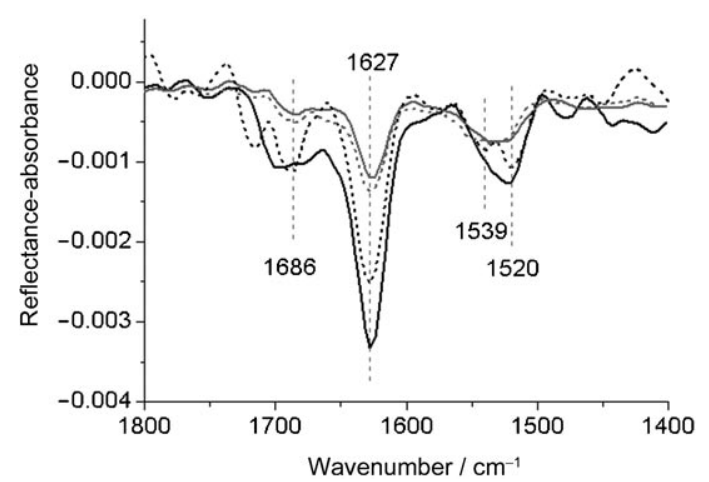

Figure 6. IRRA spectra of $\mathrm{C} / \mathrm{S}-\mathrm{Ar}-1$ and Ar-1 adsorbed to the air-buffer (containing $150 \mathrm{~mm} \mathrm{NaCl}$ ) interface. The equilibrium surface pressure is $0 \mathrm{mN} \mathrm{m}^{-1}$. Spectra were recorded at an angle of incidence of $40^{\circ}$. Solid black: C/S-Ar-1, p-polarized light, dotted black: Ar-1, p-polarized light; dotted grey: Ar-1, s-polarized light; solid grey: C/S-Ar-1, s-polarized light.

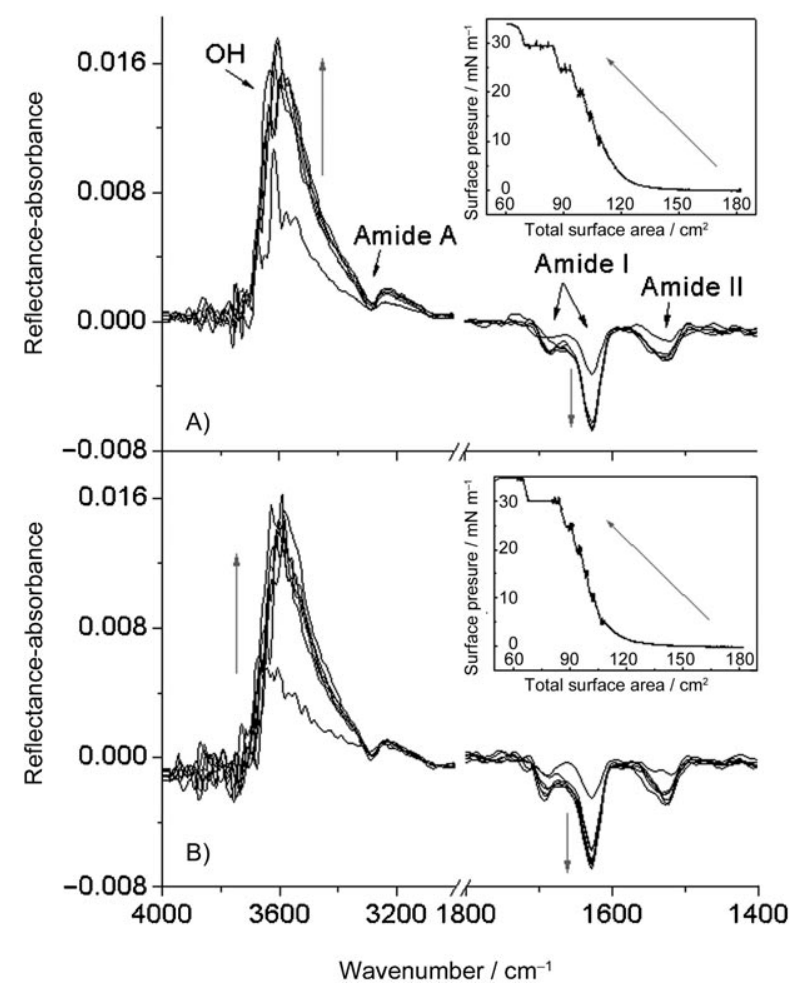

Figure 7. IRRA spectra of A) C/S-Ar-1 and B) Ar-1 adsorbed to the air-buffer (containing $150 \mathrm{~mm} \mathrm{NaCl}$ ) interface (equilibrium surface pressure is

$0 \mathrm{mN} \mathrm{m}^{-1}$ ) and then compressed to different surface pressures: $5,10,15,20$, $25,30 \mathrm{mN} \mathrm{m}^{-1}$ (the compression isotherms are inserted). Spectra have been recorded at an angle of incidence of $40^{\circ}$ with $p$-polarized light. The gray arrows show the direction of changes: The intensity of the amide and water bands increases with increasing surface pressure. sity) of the adsorption layer rapidly increases during compression, but remains constant above $\pi=10 \mathrm{mN} \mathrm{m}^{-1}$. The amide I band at $1627 \mathrm{~cm}^{-1}$ has also a constant intensity value above this surface pressure. These data correspond to the above considered maximum adsorption pressure (Figure 3 ). The dichroic ratio at different $\pi$ (not shown) increases slightly, which suggests that the in-plane ordering in the peptide adsorption layer is increasing. Above $30 \mathrm{mN} \mathrm{m}^{-1}$, the monolayer becomes unstable and the peptides desorb from the air-buffer interface.

\subsection{Packing in the Peptide Layer}

The question arose whether this adsorption layer is crystalline with well-ordered structures, which can be studied using grazing incidence X-ray diffraction (GIXD). Indeed, Bragg peaks have been observed. A weak and relatively broad Bragg peak corresponding to the interstrand distance defined by the hydrogen-bond network in a $\beta$-sheet conformation has been found at $1.317 \AA^{-1}$ on the $\mathrm{NaBr}$ containing subphase, corresponding to a repeat distance of $4.77 \AA$, and at $1.312 \AA^{-1}$ on the $\mathrm{Na}_{2} \mathrm{SeO}_{4}$ containing subphase, corresponding to a repeat distance of $4.79 \AA$ (Figure 8).

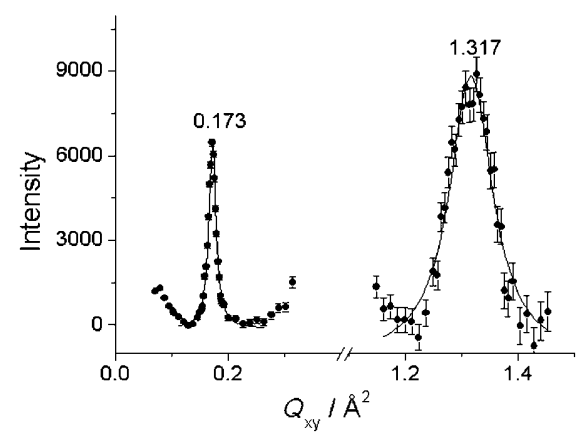

Figure 8. Bragg peaks (in-plane scattering vector component) of the C/S-Ar1 adsorption layer at the air-buffer interface. Surface pressure is $9 \mathrm{mN} \mathrm{m}^{-1}$.

The intensity and position of this peak does not vary during the compression of the film. The resolution-corrected fullwidth at half-maximum (FWHM) of this peak shows a correlation length of only $61 \AA$ on the $\mathrm{NaBr}$ containing subphase and of $67 \AA$ on the $\mathrm{Na}_{2} \mathrm{SeO}_{4}$ containing one. From the FWHM of the Bragg rod a thickness of the diffracting layer of $14.6 \AA$ on the $\mathrm{Na}_{2} \mathrm{SeO}_{4}$ subphase has been obtained. A second Bragg peak can be seen at lower $Q_{x y}$ values. This peak has been interpreted as an end-to-end distance of aligned $\beta$-sheets. ${ }^{[20]}$ Its position does also not substantially change during compression. On the $\mathrm{NaBr}$-containing subphase, the observed repeat distance amounts to $36.3 \AA$, whereas on the $\mathrm{Na}_{2} \mathrm{SeO}_{4}$-containing subphase a value of $34.1 \AA$ has been observed. The correlation lengths in the longitudinal direction amount to $425 \AA$ on $\mathrm{NaBr}$ and to $369 \AA$ on $\mathrm{Na}_{2} \mathrm{SeO}_{4}$. 


\subsection{Thickness of the Peptide Layer}

The XR curves and the corresponding electron density profiles for an C/S-Ar-1 adsorption layer on two different subphases at a surface pressure of $20 \mathrm{mN} \mathrm{m}^{-1}$ are shown in Figure 9. The ob-
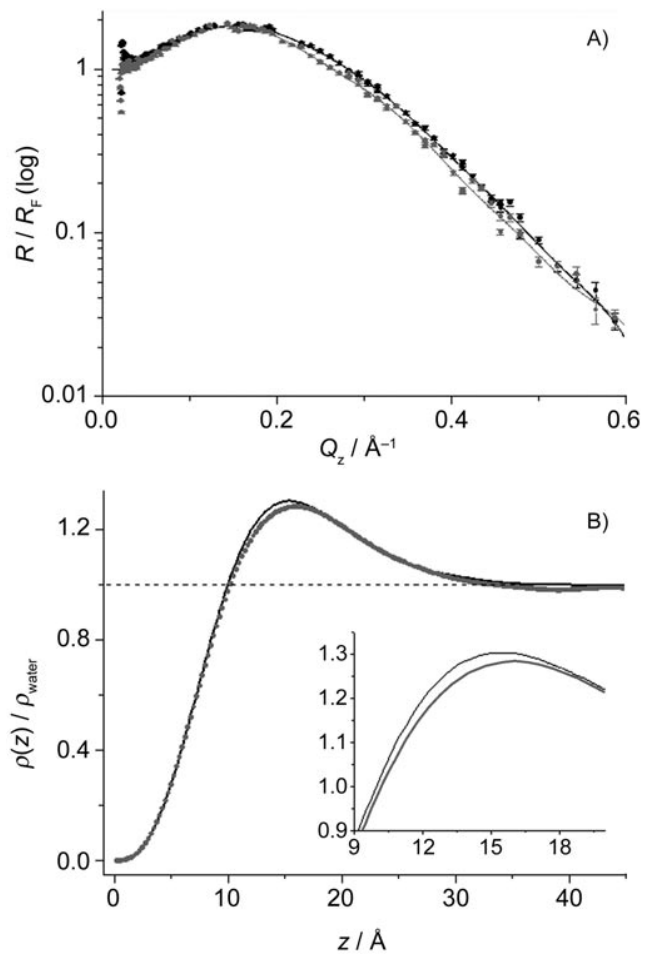

Figure 9. A) Specular X-ray reflectivity normalized by the Fresnel reflectivity, $\mathrm{R} / \mathrm{R}_{\mathrm{F}}$ for a C/S-Ar-1 adsorption layer at the buffer/air interface on $\mathrm{NaBr}$ (black) or $\mathrm{Na}_{2} \mathrm{SeO}_{4}$ (gray) containing subphases. The corresponding model reflectivity curves are shown as solid lines. B) Electron density profiles of the C/S-Ar-1 adsorption layer normalized by the electron density of water, $\rho /$ $\rho_{\text {water }}$ versus the depth $z$, corresponding to model reflectivity curves fitted to the experimentally observed ones. Inserted is an extended part of the electron density profiles. The surface pressure is $20 \mathrm{mN} \mathrm{m}^{-1}$.

served electron density profile of arenicin can be described by one-box model with a thickness of $13.3 \AA$ on the $\mathrm{NaBr}$-containing subphase and of $14.8 \AA$ on the $\mathrm{Na}_{2} \mathrm{SeO}_{4}$-containing subphase. The roughness of the adsorption layer is only $4 \AA$ showing that the peptide layer is tightly packed and quite smooth. The agreement of the layer thicknesses determined by XR and GIXD is extremely good.

The X-ray reflectivity curves for $\mathrm{NaBr}$ and $\mathrm{Na}_{2} \mathrm{SeO}_{4}$ are only slightly different, but this difference is beyond the error limit. This is also reflected in the electron density profile in the inset of Figure $9 \mathrm{~B}$. The similarity of the profiles with a slightly higher maximum electron density for the $\mathrm{NaBr}$-containing subphase results from the fact that twice the amount of monovalent $\mathrm{Br}^{-}$ is electrostatically connected to the peptide layer compared with the divalent $\mathrm{SeO}_{4}{ }^{2-}$ which has slightly fewer than twice the number of electrons as $\mathrm{Br}^{-}$.

The layer thickness of $13-15 \AA$, depending on the ions in the subphase, does not agree with the usually observed value for a $\beta$-sheet lying flat at the surface (approximately $10 \AA$ ). This can be explained by assuming that the peptide molecules at the air-water interface do not only have a turn between two $\beta$-strands, but that they are also twisted or bent in the middle of each $\beta$-sheet part of the molecule (Figure 10).

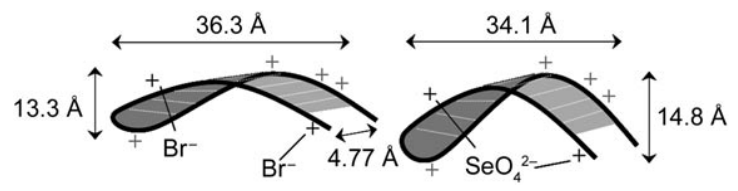

Figure 10. Conformation of the adsorbed peptide on subphases containing mono- or divalent counterions. The differences in length appear small, but they are beyond the error limit ( $1 \%$ for the lateral periodic distance).

\section{Conclusions}

The CD spectra of arenicin-1 (Ar-1) and its linear derivative C/SAr-1 indicate that both peptides show similar structures in different solvents. In the buffer used for all other experiments, fitting of the CD data led to approximately $22 \% \beta$-turn, $38 \% \beta$ sheet and $38 \%$ random coil.

Both peptides are surface-active. The adsorbed peptides form anti-parallel $\beta$-sheets, which are lying more or less flat at the interface. The surface activity is drastically increased by increasing the ionic strength of the subphase. A possible explanation for this observation is that the counterions interact strongly with the charged amino acids of the peptide and reduce thereby the effective charge of the peptide. Highly charged peptides do not adsorb to a large extent to the air/ water interface because of strong repulsive interactions with image charges. A less charged peptide experiences less repulsion with the corresponding image charges. The type of ions used has no significant influence.

The peptide $\beta$-sheet layer is quite stable. The desorption occurs much slower than the adsorption, and therefore the adsorption layer can be kept in a metastable state and can be compressed to reasonably high surface pressures.

The $\beta$-sheet layer is very crystalline. The Bragg peak corresponding to the interstrand distance defined by the hydrogenbond network in a $\beta$-sheet conformation has been observed in all cases. This distance does not change during compression. Interestingly, the $\beta$-sheet plates form an additional periodicity. The observed end-to-end distances coincide well with half the length of the peptide in a fully extended configuration. This shows that the peptide remains as a hairpin forming anti-parallel intramolecular beta-sheets (with a beta-turn) at the interface. The observed dependence of the end-to-end distance on the type of counterion used can be connected with the observed differences in the layer thickness. On the $\mathrm{Br}^{-}$containing subphase, the end-to-end distance is larger and the thickness smaller whereas on the $\mathrm{SeO}_{4}{ }^{2-}$ containing subphase a shorter end-to-end distance and a larger layer thickness have been observed. This can be explained by the assumption that the bending of the peptide depends on the interactions with the counterions. This has been schematically illustrated in 
Figure 10. More monovalent $\mathrm{Br}^{-}$can be found in the vicinity of the adsorbed peptide, which explains the slightly higher electron density observed in the XR experiments (Figure 9). On the other hand, the divalent counterion can bind to two different charges at the peptide at the same time, leading to a stronger bending of the peptide connected with a larger layer thickness and a shorter end-to-end distance (Figure 10).

\section{Experimental Section}

Materials: Both the cyclic peptide arenicin-1 (Ar-1) and its linear derivative C/S-Ar-1 with molecular weights of 2758.3 and $2728.2 \mathrm{~g} \mathrm{~mol}^{-1}$, respectively, and amino acid sequences RWCVY AYVRV RGVLV RYRRC W and RWSVY AYVRV RGVLV RYRRS W, respectively, were synthesized with an acidic C-terminus and purified as described earlier. ${ }^{[7,11]}$ Stock solutions $\left(c=1 \mathrm{mg} \mathrm{mL}^{-1}\right)$ were prepared by dissolving the peptide in phosphate buffer solution $(1 \mathrm{~mm}$, $\mathrm{pH}$ 7.4).

Phosphate buffer $\mathrm{K}_{2} \mathrm{HPO}_{4} / \mathrm{KH}_{2} \mathrm{PO}_{4}$ (Fluka/Merck), $1 \mathrm{~mm}$, pH 7.4, was used as subphase without any additional salt or with $150 \mathrm{~mm}$ $\mathrm{NaCl}, 150 \mathrm{~mm} \mathrm{NaBr}$, or $50 \mathrm{~mm} \mathrm{Na}_{2} \mathrm{SeO}_{4}$. The two last salts are selected to compare different anion valencies, and to enhance the contrast for X-Ray reflectivity experiments (Se exibits a similar electron density as $\mathrm{Br}$ ). The $\mathrm{pH}$ values were measured with a microprocessor-pH-meter (Type CG840, Schott, Germany) that was calibrated with $\mathrm{pH} 4.0,7.0$ and 10.0 buffers.

The conformation of Arenicin in bulk was studied in 2,2,2-trifluoroethanol (TFE) from Fluka and in aqueous surfactant solutions below and above the corresponding $\mathrm{cmc}$ : octyl- $\beta$-D-glucopyranosid (OG, $10 \mathrm{~mm}$ and $50 \mathrm{~mm}$ ) (GLYCON Biochemicals GmbH, Luckenwalde), sodium dodecylsulfate (SDS, $5 \mathrm{~mm}$ and $15 \mathrm{~mm}$ ) (Sigma-Aldrich) and cetyltrimethylammonium bromide (CTAB, $0.5 \mathrm{~mm}$ and $1.5 \mathrm{~mm}$ ) from Fluka. Surfactants were used without additional purification.

All aqueous solutions were prepared using ultrapure water (specific resistance of $18.2 \mathrm{M} \Omega \mathrm{cm}$ ) produced by a Millipore reverse osmosis unit.

Circular Dichroism Spectroscopy (CD): Circular dichroism spectroscopy (CD) was used for the determination of the peptide secondary structure in solution. CD spectra were recorded on a Jasco J715 (Japan) spectrometer in a wavelength range from 180 to $300 \mathrm{~nm}$ with $0.2 \mathrm{~nm}$ step resolution using quartz cuvettes with an optical path length of $0.1 \mathrm{~cm}$. The signal-to-noise ratio was improved by accumulating 10 scans. For all experiments, the peptide concentration was kept constant $\left(0.2 \mathrm{mg} \mathrm{mL}^{-1}\right)$ and the peptide was added into the solutions directly before starting the measurements. All measurements were performed at $20^{\circ} \mathrm{C}$. Data processing was carried out using the J-700 software package. The measured $C D$ signal was transformed into mean residue molar ellipticity. The blank spectra of the pure subphase were subtracted. To analyze the content of the secondary structure elements, the CONTIN method was used. ${ }^{[21]}$

Langmuir Film Balance: All adsorption experiments and other studies at the air-water interface were performed in PTFE Langmuir troughs (Riegler\&Kirstein, Potsdam, Germany), equipped with barriers for changing the surface area, and a Wilhelmy microbalance with filter paper plate for measuring the surface pressure of the monolayer. This technique was described in detail elsewhere. ${ }^{[22]}$ The temperature of the subphase was kept constant at $(20 \pm$ $0.5)^{\circ} \mathrm{C}$. The trough was filled with the subphase containing the peptide in various concentrations. After filling the solution into the
Langmuir trough, the surface was cleaned and the adsorption of the peptide was measured starting from a bare surface $(\pi=$ $0 \mathrm{mN} \mathrm{m}^{-1}$ ). The equilibrated adsorption layer was compressed and the compression isotherms were recorded.

Infrared Reflection Absorption Spectroscopy (IRRAS): IRRAS spectra were recorded using the VERTEX 70 spectrometer (Bruker, Germany) equipped with a liquid nitrogen-cooled MCT detector. The IR beam was conducted out of the spectrometer and focused onto the water surface of the Langmuir trough. A detailed description of the instrumental setup has been given elsewhere. ${ }^{[23-27]}$ The angle of incidence of the IR beam, polarized by a $\mathrm{BaF}_{2}$ polarizer in the plane of incidence $(p)$ or perpendicular to this plane $(s)$, with respect to the surface normal was $40^{\circ}$. Measurements were made by switching between two troughs at regular intervals using a trough shuttle system controlled by the acquisition computer. One trough contains the monolayer system under investigation (sample), whereas the other (reference) is filled with the pure subphase. The spectra from the reference trough were subtracted from the sample spectra in order to eliminate the water vapor signal. To maintain a constant water vapor content, the setup was placed in a hermetically sealed container. Spectra were recorded with a spectral resolution of $8 \mathrm{~cm}^{-1}$ and accumulated using 200 (for s-polarized light) and 400 (for $p$-polarized light) scans.

IRRAS data are reported as plots of reflectance-absorbance (RA) vs. wavenumber. RA is defined as $-\lg \left(R / R_{0}\right)$, where $R$ is the reflectivity of the film-covered surface and $R_{0}$ is the reflectivity of the bare subphase. RA values may be positive or negative depending on the state of polarization of the incident light and the angle of incidence with respect to the Brewster angle.

Two types of spectral information result from IRRAS measurements: frequencies and intensities. Frequencies are easier to interpret, and they provide information about the molecular structure and interactions. The most useful information about the peptide secondary structure comes from amide I frequencies (mostly peptide bond $\mathrm{C}=\mathrm{O}$ stretch). Changes in intensities can be correlated with changes in the amount of the substance at the air-water interface. This can be used, for instance, for following the adsorption process. However, intensities of bands depend also on the direction of the transition dipole moment, and simulations can provide information about molecular orientation. ${ }^{[28,29]}$

Grazing Incidence X-Ray Diffraction (GIXD): Grazing incidence XRay diffraction was measured using the liquid-surface diffractometer at the undulator beamline BW1 at HASYLAB, DESY, Hamburg (Germany). Details are given elsewhere. ${ }^{[30-33]}$ The Langmuir-film balance was thermostated at $20^{\circ} \mathrm{C}$ and placed into a hermetically closed container filled with helium. The Langmuir trough was equipped with a single movable barrier and a Wilhelmy plate for monitoring the surface pressure. The synchrotron beam, made monochromatic $(\lambda=1.3038 \AA)$ by a Be monochromator crystal, was deflected towards the sample and struck the surface at an angle of incidence $\alpha_{i}$, which is $85 \%$ of the critical angle for total external reflection $\alpha_{c} \sim 0.13^{\circ}$. A linear position-sensitive detector (PSD) was mounted vertically behind a horizontally collimating Soller slit, and was used to monitor the diffracted intensity as a function of the vertical scattering angle $\alpha_{f}$. The horizontal scattering angle $2 \theta$ was varied by rotating the entire assembly (Soller and PSD) around a vertical axis through the centre of the sample. This allows resolving the scattering simultaneously in terms of both the horizontal component $Q_{x y}$ and vertical component $Q_{z}$ of the scattering vector.

The in-plane component (i. e. the position of maximum Bragg peak intensity, $\left.Q_{x t}^{h k}\right)$ provides information about the lattice spacing $d_{h k}$ ( $h$ and $k$ are the Miller indices) [Eq. (1)]: 
$d_{h k}=\frac{2 \pi}{Q_{x y}^{h k}}$

whereas the out-of-plane component provides information about the polar tilt angle $t$ and the chain tilt direction $\Psi$ (azimuth $\Psi$ ) [Eq. (2)]:[30,31]

$Q_{z}^{h k}=Q_{x y}^{h k} \cos \Psi_{h k} \tan t$

The full-width at half-maximum (FWHM) of the Bragg peaks, $\Delta Q_{x y}$ yields the in-plane correlation length [Eq. (3)]:

$\xi_{x y} \approx \frac{0.88 \cdot 2 \pi}{\Delta Q_{x y}}$

The FWHM of the Bragg rods, $\Delta Q_{z}$ gives an estimate of the film thickness [Eq. (4)]:

$h_{z} \approx \frac{0.88 \cdot 2 \pi}{\Delta Q_{z}}$

The intensities of the scattered radiation were corrected for polarization, footprint area, and powder averaging. Model peaks taken to be Lorentzian in the in-plane direction (Bragg peak) and Gaussian in the out-of-plane direction (Bragg rod) were fitted to the corrected intensities.

Specular X-Ray Reflectivity (XR): The specular X-Ray reflectivity (XR) measurements were performed with the same instrument as the GIXD experiments on the indulator beamline BW1 at HASYLAB, DESY (Hamburg, Germany). ${ }^{[34,35]}$ XR provides an averaged electron density profile normal to the interface of all lipid and peptide components, which complements the in-plane information from GIXD. For reflectivity measurements, the angles of incident $\alpha_{\mathrm{i}}$ and reflected $\alpha_{\mathrm{f}}$ beams are equal and varied in a range $0.5 \alpha_{\mathrm{c}}<\alpha_{\mathrm{i}}\left(\alpha_{\mathrm{f}}\right)<30 \alpha_{\mathrm{c}}$ where $\alpha_{\mathrm{c}}=0.13^{\circ}$. The reflected intensity was measured by a $\mathrm{Nal}$ scintillation detector in the plane of incidence as a function of the vertical scattering vector component $Q_{z}$. The electron density profile was obtained from the reflectivity curve using a linear combination of b-splines following the approach of Pedersen and Hamley. ${ }^{[36,37]}$ For interpretation of the electron-density profiles, a box model with a certain number of adjustable parameters was applied.

\section{Acknowledgements}

We gratefully acknowledge beamtime and support at $H A S Y L A B$, DESY (Hamburg, Germany).

Keywords: adsorption · peptides · circular dichroism • infrared reflection absorption spectroscopy $\cdot \mathrm{X}$-ray diffraction

[1] P. Bulet, R. Stocklin, L. Menin, Immunol. Rev. 2004, 198, 169-184.

[2] M. Zasloff, Nature 2002, 415, 389-395.

[3] G. Wang, X. Li, Z. Wang, Nucleic Acids Res. 2009, 37, D933-937.

[4] R. M. Dawson, Ch.-Q. Liu, Crit. Rev. Microbiol. 2008, 34, 89-107.

[5] M. R. Yeaman, N. Y. Yount, Pharmacol. Rev. 2003, 55, 27-55.
[6] T. V. Ovchinnikova, G. M. Aleshina, S. V. Balandin, A. D. Krasnodembskaya, M. L. Markelov, E. I. Frolova, Y. F. Leonova, A. A. Tagaev, E. G. Krasnodembsky, V. N. Kokryakov, FEBS Lett. 2004, 577, 209-214.

[7] J. Andrä, I. Jakovkin, J. Grötzinger, O. Hecht, A. D. Krasnodembskaya, T. Goldmann, T. Gutsmann, M. Leipe, Biochem. J. 2008, 410, 113-122.

[8] C. Park, D. G. Lee, Biochim. Biophys. Acta Biomembr. 2009, 1788, 1790 1796.

[9] J.-U. Lee, K. H. Park, J.-Y. Lee, J. Kim, S. Y. Shin, Y. Park, K.-S. Hahm, Y. Kim, Bull. Korean Chem. Soc. 2008, 29, 1190-1194.

[10] J.-U. Lee, D.-I. Kang, W. L. Zhu, S. Y. Shin, K.-S. Hahm, Y Kim, Biopolymers 2007, 88, 208-216.

[11] J. Andrä, M. U. Hammer, J. Grötzinger, I. Jakovkin, B. Lindner, E. Vollmer H. Fedders, M. Leippe, T. Gutsmann, Biol. Chem. 2009, 390, 337-349.

[12] T. V. Ovchinnikova, Z. O. Shenkarev, K. D. Nadezhdin, S. V. Balandin, M. N. Zhmak, I. A. Kudelina, E. I. Finkina, V. N. Kokryakov, A. S. Arseniev, Biochem. Biophys. Res. Commun. 2007, 360, 156-162.

[13] A. Stavrakoudis, I. G. Tsoulos, Z. O. Shenkarev, T. V. Ovchinnikova, Biopolymers 2009, 92, 143-155.

[14] T. V. Ovchinnikova, Z. O. Shenkarev, S. V. Balandin, K. D. Nadezhdin, A. S. Paramonov, V. N. Kokryakov, A. S. Arseniev, Biopolymers 2008, 89, $455-$ 464.

[15] D. Blaudez, J. M. Turlet, J. Dufourcq, D. Bard, T. Buffeteau, B. Desbat, J. Chem. Soc. Faraday Trans. 1996, 92, 525-530.

[16] F. Bringezu, M. Majerowicz, E. Maltseva, S. Wen, G. Brezesinski, A. J. Waring, ChemBioChem 2007, 8, 1038-1047.

[17] C. Olak, A. Muenter, J. Andrä, G. Brezesinski, J. Pept. Sci. 2008, 14, 510 517.

[18] G. Socrates, Infrared and raman characteristic group frequencies: Tables and charts, 3rd ed., Wiley, New York, 2001.

[19] G. J. Thomas, B. Prescott, D. W. Urry, Biopolymers 1987, 26, 921 -934.

[20] M. Hoernke, B. Koksch, G. Brezesinski, Biophys. Chem. DOI: 10.1016/ j.bpc.2010.02.014

[21] N. Sreerama, R. W. Woody, Anal. Biochem. 2000, 287, 252-260.

[22] G. Brezesinski, H. Möhwald in Molecular interfacial fenomena of polymers and biopolymers (Ed.: P. Chen), Woodhead, Cambridge, 2005, pp. 286 322.

[23] R. Mendelsohn, J. W. Brauner, A. Gericke, Annu. Rev. Phys. Chem. 1995, 46, 305-334.

[24] C. R. Flach, A. Gericke, R. Mendelsohn, J. Phys. Chem. B 1997, 101, 58 -

[25] T. D. Andreeva, J. G. Petrov, G. Brezesinski, H. Möhwald, Langmuir 2008, 24, $8001-8007$

[26] M. Lepère, A. H. Muenter, C. Chevallard, P. Guenoun, G. Brezesinski, Colloids Surf. A 2007, 303, 73-78.

[27] H. Muenter, J. Hentschel, H. G. Börner, G. Brezesinski, Langmuir 2008 24, 3306-3316.

[28] E. Maltseva, A. Kerth, A. Blume, H. Möhwald, G. Brezesinski, ChemBioChem 2005, 6, 1817-1824.

[29] G. Brezesinski, E. Maltseva, H. Möhwald, Phys. Chem. 2007, 221, 95-111.

[30] J. Als-Nielsen, D. Jaquemain, K. Kjaer, M. Lahav, F. Levellier, L. Leiserowitz, Phys. Rep. 1994, 246, $251-313$

[31] K. Kjaer, Phys. B 1994, 198, 100-109.

[32] R. Rietz, W. Rettig, G. Brezesinski, W. G. Bouwman, K. Kjaer, H. Möhwald, Thin Solid Films 1996, 285, $211-215$

[33] M. Lepere, C. Chevallard, G. Brezesinski, M. Goldmann, P. Guenoun, Angew. Chem. 2009, 121, 5105-5109; Angew. Chem. Int. Ed. 2009, 48, 5005-5009.

[34] G. Brezesinski, D. Vollhardt, ChemPhysChem 2008, 9, 1670-1672.

[35] G. Brezesinski, D. Vollhardt, K. limura, H. Cölfen, J. Phys. Chem. C 2008 $112,15777-15783$.

[36] J. S. Pedersen, I. W. Hamley, Phys. B 1994, 198, 16-23.

[37] J. S. Pedersen, I. W. Hamley, J. Appl. Crystallogr. 1994, 27, 36-49.

Received: June 10, 2010

Published online on September 2, 2010 